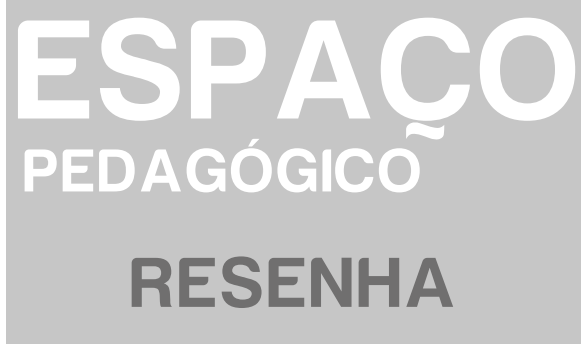




\section{Aprendizagem significativa: a teoria de David Ausubel}

Luiz Marcelo Darroz*

O ensino de ciências tem assumido um espaço importante no processo de formação de cidadãos críticos, éticos e com capacidade de interpretar o mundo à sua volta. Tal fato evidencia a necessidade do desenvolvimento de novas metodologias que possibilitem aos estudantes fazer a associação dos assuntos estudados nos bancos escolares com a sua vivência cotidiana.

Nessa direção, buscando estratégias de ensino que proporcionem a interação dos assuntos escolares com os conhecimentos contidos na mente dos estudantes, a teoria da aprendizagem significativa, proposta por David Paul Ausubel em 1963, tem sido muito utilizada por pesquisadores e especialistas da área, para fundamentar suas propostas. Por esse motivo, muitas obras vêm sendo publicadas com vista a difundir os princípios que estruturam essa teoria.

O livro de Marco Antônio Moreira e Elcie Aparecida Fortes Salzano Masini, intitulado Aprendizagem significativa: a teoria de David Ausubel, é um exemplo que se destaca, por apresentar os elementos da teoria da aprendizagem significativa de forma simples, objetiva e de fácil compreensão. A obra inicia com a constatação dos autores de que a aprendizagem é muito mais do que uma simples execução de comandos, e é necessário colocar o aprendiz como sujeito ativo nesse processo.

A partir dessas concepções, bem como da compreensão de que cada indivíduo apresenta conhecimentos sobre diversos aspectos, e os simples fatos de nascer e viver são suficientes para inserir elementos na mente de uma pessoa, o primeiro capítulo, "A Teoria Cognitiva da Aprendizagem", discute os elementos estruturantes da teoria da aprendizagem significativa. Ainda na abertura do capítulo, evidencia-se que a teoria prioriza a aprendizagem cognitiva, e a aprendizagem significativa é o processo pelo qual o novo conhecimento se articula a uma determinada estrutura cognitiva prévia, denominada subsunçor.

No decorrer da obra, os autores revelam que Ausubel defende a ideia de que a nova informação se vincula a aspectos relevantes preexistentes na estrutura cognitiva, e, nesse processo, ambas se modificam. Tal estrutura é concebida como o

Recebido em 29/09/2017 - Aprovado em 04/02/2018

http://dx.doi.org/10.5335/rep.v25i2.8180

Doutor em Educação em Ciências pela Universidade Federal do Rio Grande do Sul. Professor de Física na Universidade de Passo Fundo e docente permanente do Programa de Pós-Graduação em Ensino de Ciências e Matemática na mesma instituição. E-mail: Idarroz@upf.br 
conjunto de conteúdos informacionais e a maneira como estão organizados na mente de um indivíduo. Os subsunçores, por sua vez, consistem em conceitos ou noções já existentes na estrutura cognitiva, capazes de servir de "pontos de ancoragem" que contribuirão para que as novas informações encontrem um modo de se integrar àquilo que a pessoa já conhece.

A aprendizagem significativa contrasta, fundamentalmente, com a aprendizagem mecânica, na medida em que, na primeira, a nova informação interage com algum subsunçor existente na estrutura cognitiva, já, na segunda, a nova informação não interage com informações existentes na estrutura cognitiva; assim, pouco ou nada contribui para a sua elaboração e a sua diferenciação. Para Ausubel, porém, essas duas formas de aprendizagem se complementam, pois a segunda pode levar à primeira. Muitas vezes, um indivíduo pode aprender mecanicamente e só mais tarde perceber que esse aprendizado se relaciona com algum conhecimento anterior já dominado.

Existem algumas condições para que a aprendizagem significativa ocorra. A primeira é que o material a ser aprendido tenha estruturação lógica e possa ser relacionado com a estrutura cognitiva do estudante, de maneira não arbitrária e não literal, sendo assim considerado potencialmente significativo. A segunda condição para a ocorrência da aprendizagem significativa é a apresentação de uma disposição para aprender significativamente por parte do estudante, para tanto ele não pode ter a intenção de memorizar ou de decorar o material. Quando uma das duas condições não for satisfeita, ocorrerá, segundo Ausubel, uma aprendizagem mecânica.

Para facilitar a aprendizagem significativa, Moreira e Masini salientam que Ausubel recomenda o uso de organizadores prévios, que correspondem a materiais a serem propostos antes da utilização do material de aprendizagem, servindo de ponte entre o conhecimento prévio e os assuntos que se pretendem ensinar. Os indícios da ocorrência da aprendizagem significativa, por sua vez, são obtidos quando o estudante consegue desenvolver e transferir os assuntos trabalhados a novas situações.

O processo de aquisição e organização de novos conhecimentos na estrutura cognitiva de um estudante é chamado por Ausubel de "teoria da assimilação". Em tal teoria, uma nova informação potencialmente significativa é relacionada e assimilada a um conceito subsunçor preexistente na estrutura cognitiva do estudante. Como resultado dessa relação e assimilação, tem-se o produto interacional, isto é, o subsunçor modificado. Assim, a nova informação é subordinada aos conceitos subsunçores preexistentes. 
A aprendizagem em que a nova informação, mais geral que os subsunçores preexistentes, é adquirida e assimilada pela estrutura cognitiva do estudante chama-se de "aprendizagem superordenada". Quando os novos conceitos não estabelecem relação de subordinação ou de superordenação com um subsunçor específico, mas com um conteúdo geral presente na estrutura cognitiva do estudante, a aprendizagem é conhecida como "combinatória".

Por fim, no primeiro capítulo, os autores ressaltam, ainda, dois importantes processos que, segundo Ausubel, surgem durante a aprendizagem significativa: a "diferenciação progressiva" e a "reconciliação integrativa". A primeira ocorre quando se observa que o subsunçor se modificou a partir da introdução de uma nova informação, que também se alterou e recebeu novo significado. Já, a segunda, que acontece na aprendizagem significativa superordenada ou na combinatória, concretiza-se quando se estabelecem relações entre os conceitos já existentes na estrutura cognitiva, ou seja, quando há uma relação entre os subsunçores, que se organizam e adquirem novos significados.

Os capítulos dois, três e quatro, embora menos extensos, apresentam elementos importantes ao processo de ensino de ciências. No segundo capítulo, são discutidos a aquisição e o uso de conceitos na perspectiva da teoria da aprendizagem significativa. A obra expressa claramente que cada pessoa constrói uma base de conhecimentos, ou seja, que os conhecimentos são formados e assimilados. Quando criança, o ser humano classifica os conhecimentos utilizando-se da experiência. Posteriormente, pode assimilar conceitos mais abstratos, sem a necessidade de experimentar. Assim, os conceitos têm aspecto conotativo, e os seus significados, para Ausubel, tornam-se fenomenológicos, quando se levam em consideração os aspectos particulares da pessoa que os formulou.

A obra evidencia a importância do professor em criar e desenvolver métodos que permitam uma melhor organização da forma de ensino, auxiliando o aprendiz a explorar seu conhecimento e localizar o meio mais adequado de assimilação. Nesse sentido, o terceiro capítulo, denominado "Um modelo para planejar a instrução", discute a utilização de mapas conceituais no processo de ensino.

Os mapas conceituais são compreendidos como representações ou diagramas que indicam relações entre conceitos, ou, ainda, podem ser interpretados como diagramas hierárquicos que buscam apresentar, de forma reflexiva, a organização conceitual de um corpo de conhecimentos ou de parte dele. Os autores salientam que os mapas podem ser usados para mostrar as relações hierárquicas entre os conceitos que estão sendo ensinados numa única aula, numa unidade de estudo ou num curso inteiro. 
A obra indica que, entre as possíveis vantagens da utilização de mapas conceituais, destacam-se a possibilidade de enfatizar a estrutura conceitual de uma disciplina e o papel dos sistemas conceituais no seu desenvolvimento; a de mostrar que os conceitos de uma certa disciplina diferenciam-se quanto aos graus de inclusividade e generalidade, ao apresentar esses conceitos numa ordem hierárquica de inclusividade que facilite a sua aprendizagem e a sua retenção; e a de promover uma visão integrada do assunto em uma espécie de "listagem" daquilo que foi abordado nos materiais instrucionais. Isto é, os mapas conceituais possibilitam a identificação: da estrutura de significados aceita no contexto da matéria de ensino; dos conceitos subsunçores (significados) necessários para a aprendizagem significativa na matéria de ensino; e dos significados preexistentes na estrutura cognitiva do aprendiz. Ainda, permitem a organização sequencial do conteúdo e da seleção dos materiais curriculares, usando as ideias de diferenciação progressiva e de reconciliação integrativa como princípios programáticos; e do ensinar, usando organizadores prévios, para fazer pontes entre os significados que o aluno já tem e os que ele precisaria ter para aprender significativamente a matéria de ensino, bem como para o estabelecimento de relações explícitas entre o novo conhecimento e aquele já existente e adequado para dar significados aos novos materiais de aprendizagem.

Por fim, o quarto capítulo, intitulado "Exemplos de utilização da teoria", descreve algumas propostas de sequências de ensino de Física, de Literatura, de Língua Estrangeira e de Biologia, estruturadas com base nos pressupostos da teoria da aprendizagem significativa.

Sendo assim, a obra tem como foco a forma cognitiva de aprendizagem, e a discussão central está na ideia de que a aprendizagem será significativa ao se efetivar a interação não literal e não arbitrária entre conhecimentos prévios e conhecimentos novos. Nesse processo, os novos conhecimentos adquirem significado para o sujeito, e os conhecimentos prévios, novos significados ou maior estabilidade cognitiva.

\section{Referência}

MOREIRA, M. A.; MASINI, E. F. S. Aprendizagem significativa: a teoria de David Ausubel. São Paulo: Centauro, 2006. 